\section{An unique encounter with paraprotenemia}

Sir,

Our laboratory received a patient's sample in a yellow-capped gel-containing Vacutainer requesting for the estimation of calcium, creatinine, C-reactive protein (CRP), electrolytes, uric acid, and Vitamin D. Visual inspection of the primary sample tube did not reveal any discrepancies. Portions of the sample were dispensed to analyze all the requested analytes. The investigations revealed elevated levels of serum uric acid $(10.7 \mathrm{mg} / \mathrm{dl})$, reduced serum sodium $(129 \mathrm{mmol} / \mathrm{L})$, moderately elevated serum creatinine $(1.26 \mathrm{mg} / \mathrm{dl})$, and normal CRP levels.

The estimation of serum Vitamin D faced a difficulty as the autoanalyzer was generating instrument alarms such as "Assay cup not found" and "Pre-wash assay cup pick up error," indicating a technical error. With the alarms, the analyzer came to a "stop" mode initially and then entered into "stand by" mode, thus terminating performance of tests on all the loaded samples. After the necessary remedial actions as suggested in the operator's manual (Cobas ${ }^{\circledR} 6000$ analyzer series operator's manual, Roche Diagnostics), the analyzer resumed to function. The error codes appeared after incubation of the specimen with reagents for Vitamin D on the e601 module of Cobas ${ }^{\circledR} 6000$ analyzer. Another attempt to analyze Vitamin D on the same sample resulted in similar consequences. It was observed during rerun; the pipette probe was unable to transfer the reaction mixture from the reaction cup into the measuring cell. The reaction mixture had turned into a semisolid material that adhered to the probe along with the light-weighted reaction cup which was pulled out of the rack [Figure 1]. ${ }^{[1]}$ The technical assistance was sought for the rectification of issues, thus leading to the following unforeseen consequences of significant instrument downtime, increased turnaround time, and delayed patient reporting. The Vitamin D test literature (reagent kit insert) was reviewed to find the probable interferences. None of the mentioned interferences were able to explain the present scenario. Serum Vitamin D estimation was not possible.

The following day, the same patient's sample was received in a gel-containing Vacutainer (yellow top tube) for the estimation of liver function tests (LFTs). After centrifugation, it was noted that serum sample was sandwiched between the clot and the floating gel. This suggested that the patient may be a case of paraproteinemia. Hence, a request was being made to collect the sample in a lithium heparin tube (light green

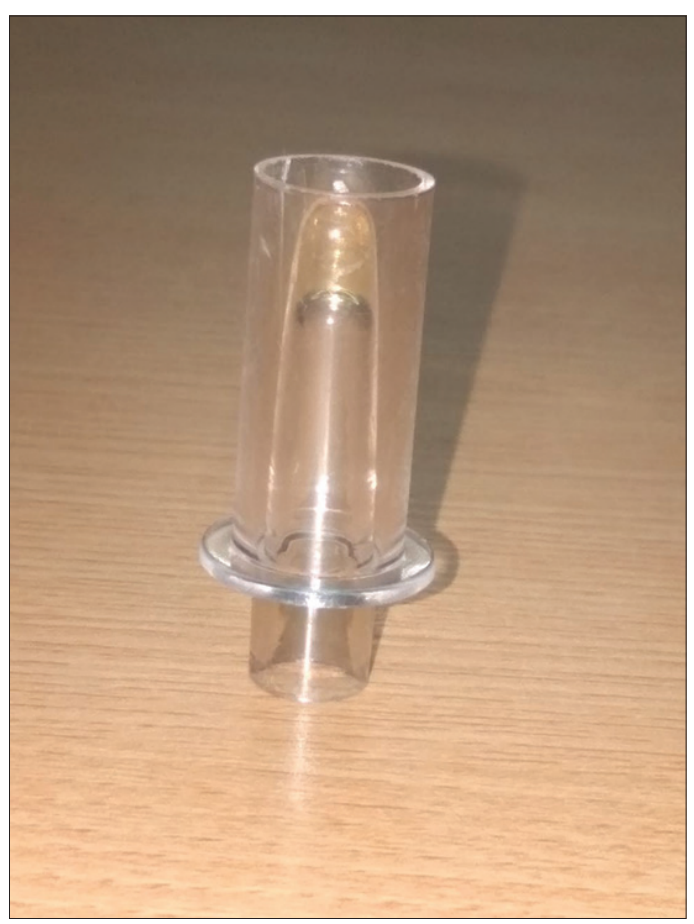

Figure 1: The serum sample transformed into a semisolid material after incubation with Vitamin D reagents

top tubes). Proper separation of the serum was achieved for the analysis of LFT to reveal extremely high serum total protein levels of $16.1 \mathrm{~g} / \mathrm{dl}$ and serum albumin of $1.8 \mathrm{~g} / \mathrm{dl}$.

Circulating paraproteins are found in patients with multiple myeloma or lymphoproliferative disorders. They differ from other common endogenous interferents as they cannot be detected by discoloration of serum or plasma. Paraprotein interferences cause pseudohyponatremia, pseudohypoglycemia, artifactual hyperbilirubinemia, artifactually low high-density lipoprotein cholesterol, pseudohyperphosphatemia or hypophosphatemia, factitious hypouricemia, factitious hypoalbuminemia, spurious underestimation of urea, underestimation of creatinine, underestimation of thyroxine measurements, spuriously increased CRP, and increased antistreptolysin-O. ${ }^{[2]}$

\section{Mechanisms of paraprotein interference}

Paraproteinemia or hyperimmunoglobulinemia can interfere in many clinical chemistry measurements including nephelometry, turbidimetry, or immunoassays. The effect of paraproteins or immunoglobulins may be classified according to the following mechanisms: ${ }^{[2]}$

- Increasing serum or plasma viscosity due to the presence of paraproteins results in a decrease in the water compartment. Consequently, the amounts of water-soluble analytes are spuriously underestimated. This mechanism can explain the cause of pseudohyponatremia that is measured by indirect ion-selective electrode methods 
- Precipitation of paraproteins with reagents may occur during the test procedures, resulting in turbidity and its interference in nephelometric, turbidimetric, or colorimetric assays

- Paraproteins may interfere with immunoassays by interaction with the specific antibody reagents, thereby falsely increasing laboratory values

- Inhibition of all three stages of fibrin formation: the proteolytic action of thrombin on fibrinogen, the aggregation of fibrin monomers, and the stabilization of fibrin by cross-linkages in the $\gamma$ and $\alpha$ chain. Incomplete or delayed fibrin clot formation may result in the presence of latent fibrin in the form of thin strands or gelatinous masses, thus causing interferences in analysis. ${ }^{[3]}$

\section{Abnormal behavior of separator gels}

The most commonly used tubes for clinical chemistry analyses are the serum separator tubes which contain a clot activator and a polymerized gel. Micronized silica particles accelerate clot formation, by the intrinsic pathway, through clot activation. The gel is thixotropic, i.e., it is semisolid under static conditions, but becomes less viscous if force, such as centrifugation, is applied. ${ }^{[4]}$

The specific gravity of this gel is most often $1.04 \mathrm{~g} / \mathrm{cm}^{3}$ to permit its suitable positioning between serum and cellular constituents of blood upon centrifugation. The density of the liquid (serum/plasma) and cellular components of the blood typically ranges from $1.026-1.031 \mathrm{~g} / \mathrm{cm}^{3}$ and $1.092-1.095 \mathrm{~g} / \mathrm{cm}^{3}$, respectively. ${ }^{[4]}$ Due to differences in density of these components, the gel is displaced and moves upward and forms a barrier upon centrifugation, thus maintaining the integrity of both components, and prevents the crossing of molecules and proteins released from the cells to the serum.

The position of the gel after centrifugation is influenced at three levels: ${ }^{[4]}$

1. Tube characteristics: specific gravity, yield stress, viscosity, density, and tube material

2. Laboratory conditions: temperature and speed of centrifugation, acceleration and deceleration, and storage of sample

3. Patient factors: presence of heparin therapy, low hematocrit, elevated plasma protein, serum/plasma specific gravity, administration of iodinated contrast material, and contamination of the sample with trisodium citrate (Citra-Lock).

Gel floatation has been demonstrated to be linked to the relative density of the clinical specimen rather than to the relative viscosity of the specimen. A study by Faught et al. recently observed remarkable differences in the specific gravity of separator gels contained in blood collection tubes from different manufacturers, with a consequent difference in the frequency of gel flotation events.

Several case reports suggest that multiple myeloma and related disorders are associated with improper gel barrier formation. ${ }^{[3,5,6]}$ In a study of 42,080 patients whose blood was sampled into serum separator containers, only 16 had persistently abnormal separation and of these 14 had multiple myeloma (total protein concentrations 69-141 g/L, median $90 \mathrm{~g} / \mathrm{L}$ ) and two had monoclonal gammopathy of undetermined significance with protein concentrations of 88 and $65 \mathrm{~g} / \mathrm{L} .{ }^{[5]}$ This suggests that underlying myeloma may be more commonly associated with anomalous gel position than raised total protein alone, and a possible additional mechanism is the known inhibition of myeloma paraprotein with fibrin formation. ${ }^{[3]}$ Van den Ouweland and Church described impaired gel separation in two patients with multiple myeloma. ${ }^{[6]}$ In both of these cases, very high levels of total protein were noted (>130 g/L) along with elevated plasma viscosity. The nature of the monoclonal gammopathy in these two cases was IgG $\kappa$ and $\operatorname{Ig} \mathrm{A} \kappa$.

The patient's sample behaved differently in two scenarios. The first sample acted in an unique manner by forming a semisolid (gel/precipitate) material on contact with Vitamin D-estimating reagents by triggering instrument alarms (methodology of Vitamin D estimation - electrochemiluminescence) due to the presence of extremely high levels of total proteins with elevated globulins without difficulty in separation of serum. The second sample showed inappropriate floatation of the barrier gel and posed a problem for the separation of serum contrary to the first sample.

To conclude, paraprotein interferences can be highly challenging and totally unpredictable for the estimation of various biochemical parameters by either interfering with the separation of serum or by an abnormal reaction of the specimen with reagents. The present communication showcased the occurrence of both the above possibilities.

\section{Financial support and sponsorship} Nil.

\section{Conflicts of interest}

There are no conflicts of interest.

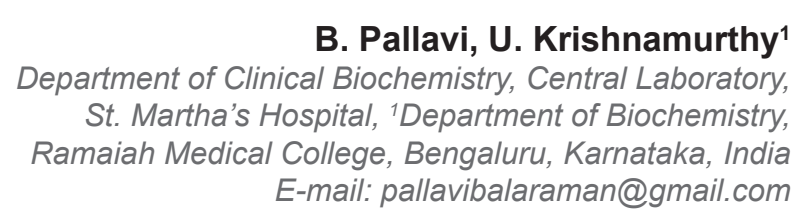




\section{References}

1. Lyon AW, Rocque LH, Corriveau S, Saunders R. Instrument error codes and diagnostic serendipity. J Applied Lab Med 2017;1:740-44.

2. Piyophirapong S, Wongtiraporn W, Sribhen K. Factitious results in clinical chemistry tests caused by common endogenous interferents. Siriraj Med J 2010;62:185-88.

3. RicoRios N, Bowles L, Ayling RM. Multiple myeloma and acquired von willebrand disease: A combined cause of preanalytical interference causing gel formation? Ann Clin Biochem 2018;55:181-4.

4. Bowen RA, Hortin GL, Csako G, Otañez OH, Remaley AT. Impact of blood collection devices on clinical chemistry assays. Clin Biochem 2010;43:4-25.

5. Chakraborty S, Chowdhury SR, Krishnan P, Sanyal S, Bhattacharya C, Sen S. Improper serum separation on gel tubes: a trivial laboratory problem or an indicator of monoclonal gammopathy? Clin Chem Lab Med 2014;52:e275-8.

6. van den Ouweland JM, Church S. High total protein impairs appropriate gel barrier formation in BD Vacutainer blood collection tubes. Clin Chem 2007;53:364-5.
This is an open access journal, and articles are distributed under the terms of the Creative Commons Attribution-NonCommercial-ShareAlike 4.0 License, which allows others to remix, tweak, and build upon the work non-commercially, as long as appropriate credit is given and the new creations are licensed under the identical terms.

\begin{tabular}{|l|l|}
\hline \multicolumn{2}{|c|}{ Access this article online } \\
\hline Quick Response Code: & Website: \\
\hline & www.jponline.org \\
\hline & \\
\hline
\end{tabular}

How to cite this article: Pallavi $B$, Krishnamurthy $U$. An unique encounter with paraprotenemia. J Lab Physicians 2019;11:391-3.

๑ 2019 Journal of Laboratory Physicians | Published by Wolters Kluwer - Medknow 